\title{
Active and Reactive Power Losses in Distribution Transformers
}

\author{
Michal Kolcun ${ }^{1}$, Anna Gawlak ${ }^{2}$, Miroslaw Kornatka ${ }^{2}$, Zsolt \\ Čonka ${ }^{1}$
}

${ }^{1}$ Technical University of Košice, Department of Electric Power Engineering, Mäsiarska 74, 04001 Košice, Slovakia; michal.kolcun@tuke.sk;

zsolt.conka@tuke.sk

2 Technical University of Częstochowa, Faculty of Electrical Engineering, Al. Armii Krajowej 17, 42-200 Częstochowa, Poland; gawlak@el.pcz.czest.pl; kornatka@el.pcz.czest.pl

\begin{abstract}
The problem of energy quality has recently gained much recognition, one of the reasons being, that there is an increasing number of devices which require energy that meets high quality standards. An improvement in this respect, can be achieved by effective management of reactive power flow in the power system. Maintaining balance in active and reactive power is of key importance for the flawless functioning of the power system. This paper discusses theoretical issues underpinning calculations of active, reactive power and of energy loss in $M V / L V$ transformers. Based on the parameters of transformers and data from consumer meters on active and reactive power, active and reactive power and energy loss was obtained, with the view to assess the efficiency of active power and energy transfer through MV/LV transformers.
\end{abstract}

Keywords: modelling; energy losses; active and reactive energy

\section{Introduction}

The flow of current through the elements of a power network, is accompanied by power and energy losses. Loss occurring at resistive elements is known as active loss, whereas the loss occurring at reactance elements is known as reactive loss. Both kinds of loss are detrimental due to a number of reasons: the extra amount of energy has to be generated in power plants, which requires additional devices and resources; the extra energy has to be transferred through all of the network elements, which requires increasing their transfer capacity; on Joule-Lenz law, energy turns into heat, which affects the dimensions of the network elements [14]. The consequences of losses vary depending on their type and place of their occurrence. As regards transformers, the key element is the core, which is 
magnetized by means of inductive power, constituting reactive idle loss. This kind of loss can be greater than load loss and in the case of low power transformers, the ratio of idle to load loss can be about 4-5. Reactive idle loss in transformer cores is compensated for by means of capacitor batteries connected directly to the transformer [5-9]. The power of such capacitors should be equal to the power of the rated idle loss. Even though no energy resources are consumed for the generation of reactive power, which does not yield any work, it flows through the power system increasing its load. By this token, the detrimental effect of reactive power is multiplied. It is typically assessed by an equivalence coefficient of reactive power, by means of which it is possible to calculate the amount of active loss per unit of reactive power. The value of the coefficient depends on the location of the occurrence of reactive power. According to The Energy Efficiency Act [10], reducing reactive energy loss (art.19 par.1 pt. 5a) is one of the moves that should be implemented towards improving energy efficiency. In this respect, special attention should be paid to power transformers, which are one of the key elements of the power system [4, 7, 11]. Energy losses occurring in MV/LV transformers constitute from about 30 to $60 \%$ of total losses in LV networks [1214]. At present, MV/LV transformers are typically not metered, but since the number of smart meters installed at end-consumers is continuously increasing, it is possible to measure the amount of energy flowing through MV/LV transformers with large precision [15-17].

\section{Measurements of Energy Losses in a Two-Winding Transformer}

Fig. 1 presents the measurement system, including an electronic meter of electrical energy, installed at the lower-voltage side of a two-winding transformer.

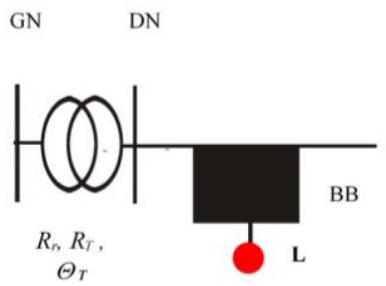

Figure 1

Measurement at the lower voltage side of a transformer

The following symbols are used in Fig. 1:

- GN - higher-voltage side

- DN - lower-voltage side 
- BB - "black box" (voltage and current transformers); the following quantities are given for the transformers:

$-\vartheta_{U}-$ winding ratio of the voltage transformer

$-\vartheta_{I}-$ winding ratio of the current transformer

- L - electronic meter

$-R_{r} \quad$ - idle resistance of the transformer

- $R_{T}$ - rated load resistance of the transformer

- $\Theta_{T}$-winding ratio of the transformer, equal to:

$\Theta_{T}=\frac{U_{G N}}{U_{D N}}(1+0,01 \cdot \Delta z)$

where: $U_{G N}-$ rated voltage of the transformer primary winding, $U_{D N}-$ rated voltage of the transformer secondary winding, $\Delta z$ - percentage correction of the transformer winding ratio.

The meter records [19] the following data:

- power profile, including active consumed power $\{P+\}_{T n}$, reactive consumed (inductive) power $\left\{Q_{L}+\right\}_{T n}$, reactive returned (capacitive) power $\left\{\mathrm{Q}_{C}-\right\}_{T n}$ at the $n$-th calculation period $T_{n}$, and possibly also active returned power $\{P-\}_{T n}$, reactive returned (inductive) power $\left\{Q_{L^{-}}\right\}_{T n}$, and reactive consumed (capacitive) power $\left\{\mathrm{Q}_{C}+\right\}_{T n}$ ),

- energy losses at the end of the $n$-th calculation period for the $z$-th zone, including losses of the active consumed energy $S P_{n z}$, of reactive consumed (inductive) energy $S Q_{L, n z}$, reactive returned (capacitive) energy $S Q_{C, n z}$, and possibly also energy states corresponding to the power profile, as enumerated above; $n$-index of the calculation period, $z=1,2, \ldots, Z, Z-$ the number of zones within 24 hours,

- indications of the loss counters: $S\left(V^{2} h\right)_{n}, S\left(I^{2} h\right)_{n}$ at the end of a $n$-th calculation period without dividing it into time zones. The values are given for the whole 24-h period and the meter does not register, unfortunately, the indications of the loss counters for each measuring cycle.

On the basis of the indications of the loss counters, the following values are obtained for the current $n$-th calculation period:

$$
\begin{aligned}
& \Delta S(V)=S\left(V^{2} h\right)_{n}-S\left(V^{2} h\right)_{n-1} \\
& \Delta S(I)=S\left(I^{2} h\right)_{n}-S\left(I^{2} h\right)_{n-1}
\end{aligned}
$$


Let us turn to active energy. At the resistance $R_{r}$ there are voltage energy losses and at the resistance $R_{T N}$ there are load energy losses. The two resistances are obtained from the formulas:

$$
\begin{aligned}
& R_{r}=\frac{U_{G N}^{2} \cdot 10^{3}}{\Delta P_{F e N}} \\
& R_{T}=\Delta P_{C u N} \frac{U_{G N}^{2}}{S_{N}^{2}} \cdot 10^{3}
\end{aligned}
$$

where: $\Delta P_{\mathrm{FeN}}-$ rated loss of the active power in the transformer core, $\mathrm{kW}$, $\Delta P_{C u N}$ - rated loss of the active power in the transformer windings, $\mathrm{kW}, S_{N}-$ rated power of the transformer, $\mathrm{kVA}, U_{G N}$ - rated voltage (see above), $\mathrm{kV}$.

The voltage loss of active energy occurs in accordance with the formula (2):

$$
\begin{aligned}
& U_{D(h)}^{2}=\Delta S(V) \vartheta_{U}^{2},\left[\mathrm{~V}^{2} \mathrm{~h}\right] \\
& U_{G(h)}^{2}=\Delta S(V) \vartheta_{U}^{2} \Theta_{T}^{2},\left[\mathrm{~V}^{2} \mathrm{~h}\right]
\end{aligned}
$$

As follows from the formula $\Delta P_{F e N}=\frac{U_{G N}^{2} \cdot 10^{3}}{R_{r}}$, the voltage energy loss $\Delta E_{U}$ is equal to (cf. (7))

$$
\Delta E_{U}=\frac{\Delta S(V) \vartheta_{U}^{2} \Theta_{T}^{2}}{R_{r} \cdot 10^{3}},[\mathrm{kWh}]
$$

After substituting (4) into (8)

$$
\Delta E_{U}=\frac{\Delta S(V) \vartheta_{U}^{2} \Theta_{T}^{2} \Delta P_{F e N}}{U_{G N}^{2} 10^{6}},[\mathrm{kWh}]
$$

The load (current) loss of the active energy occurs in accordance with (cf. (3))

$$
I_{D(h)}^{2}=\Delta S(I) \vartheta_{I}^{2},\left[\mathrm{~A}^{2} \mathrm{~h}\right]
$$

On the basis of (10) and by analogy to $\Delta P_{C u N}=3 I_{N}^{2} R_{T} \cdot 10^{-3}$, the current energy loss $\Delta E_{I}$ equals

$$
\Delta E_{I}=\Delta S(I) \vartheta_{I}^{2} R_{T(D N)} \cdot 10^{-3},[\mathrm{kWh}]
$$

where: $R_{T(D N)}$ - load resistance of the transformer at the voltage DN, equal to (cf. (1), (5)) 


$$
R_{T(D N)}=R_{T} \cdot \frac{1}{\Theta_{T}^{2}}=\Delta P_{C u N} \frac{U_{G N}^{2}}{S_{N}^{2}} \cdot \frac{10^{3}}{\Theta_{T}^{2}}
$$

After substituting (12) into (11)

$$
\Delta E_{I}=\Delta S(I) \vartheta_{I}^{2} \Delta P_{C u N} \frac{U_{G N}^{2}}{S_{N}^{2}} \cdot \frac{1}{\Theta_{T}^{2}},[\mathrm{kWh}]
$$

Active energy in the $z$-th zone equals

$$
E(P)_{z}=\left(S P_{n z}-S P_{n-1, z}\right) M,[\mathrm{kWh}]
$$

where: $M$ - constant (multiplier) of the meter, depending on the winding ratio: $\vartheta_{U}, \vartheta_{I}$

The total energy is a summation (cf. (14))

$$
E(P)=\sum_{z=1}^{Z} E(P)_{z}
$$

Electronic meters equipped with loss recording modules are typically installed at a large energy user's, with measurements performed at the DN (lower voltage) circuit of a transformer. The consumer pays, among other things, for energy consumed and energy loss occurring in the transformer, the tariffs being different for the particular zones. Therefore, the problem arises how to assign voltage and current energy losses to the particular zones. The total loss should be distributed correctly over the time zones, in order to add an appropriate value to the energy obtained (14).

\section{Calculating Power/Energy Losses in a Transformer on the Basis of Load}

A meter installed at the lower-voltage side of the transformer takes measurements at 15-minute intervals. On the basis of these measurements, mean active and reactive power, i.e. the power profile is energy $\mathrm{QL}(+) \mathrm{t}$, reactive capacitive returned energy $\mathrm{QC}(-) \mathrm{t}$, reactive inductive returned energy $\mathrm{QL}(-) \mathrm{t}$, reactive capacitive consumed energy QC(-)t can be obtained [15]:

$$
P_{t}=P(+)_{t}-P(-)_{t} ; Q_{t}=Q_{L}(+)_{t}-Q_{C}(-)_{t}-Q_{L}(-)_{t}+Q_{C}(+)_{t}
$$

Active energy in the $h$-th hour is equal to the active power $\bar{P}_{h}$ averaged over an hour 


$$
\bar{P}_{h}=\sum_{t(h)=k(h)-3}^{k(h)} P_{t(h)}
$$

and reactive energy in the $h$-th hour is equal to the reactive power $\bar{Q}_{h}$ averaged over an hour

$$
\bar{Q}_{h}=\sum_{t(h)=k(h)-3}^{k(h)} Q_{t(h)}
$$

where: $k(h)$ - number of the last quarter of the $h$-th hour, $h$ - number of the hour, $h$ $=1,2, \ldots, H, H$ - number of hours analyzed in the period under scrutiny.

Active power $P_{t}$ and reactive power $Q_{t}$ for the $t$-th 15 minute cycle are, respectively:

$$
P_{t}=3 U_{f t} I_{t} \cos \varphi_{t}=3 U_{f t} I_{c t} \quad Q_{t}=3 U_{f t} I_{t} \sin \varphi_{t}=3 U_{f t} I_{b t}
$$

where: $U_{f t}$-phase voltage for the $t$-th cycle, $I_{c t}, I_{b t}$ active and reactive current components for the $t$-th cycle, respectively, equal to:

$$
I_{c t}=\frac{P_{t}}{3 U_{f t}} \quad I_{b t}=\frac{Q_{t}}{3 U_{f t}}
$$

In a 60 -minute period consisting of four 15 -minute cycles, the active component $I_{c}$ and the reactive component $I_{b}$ of the current are (cf. (20)):

$$
I_{c}=\sum_{t} I_{c t}=\frac{1}{3} \sum_{t} \frac{P_{t}}{U_{f t}} \quad I_{b}=\sum_{t} I_{b t}=\frac{1}{3} \sum_{t} \frac{Q_{t}}{U_{f t}}
$$

and their resultant sum $I$ is

$$
I=\sqrt{I_{c}^{2}+I_{b}^{2}}
$$

Substituting (21) into (22)

$$
I=\frac{1}{3} \sqrt{\left(\sum_{t} \frac{P_{t}}{U_{f t}}\right)^{2}+\left(\sum_{t} \frac{Q_{t}}{U_{f t}}\right)^{2}}
$$

On the basis of mean power/hour (por. (17), (18); the index $h$ was dropped), the apparent power is obtained

$$
S=\sqrt{\bar{P}^{2}+\bar{Q}^{2}}
$$


On the basis of (24) and the formula $S=\sqrt{3} \bar{U} I$, the mean line-to-line voltage in an hour is obtained

$$
\bar{U}=\frac{\sqrt{3\left[\left(\sum_{t} P_{t}\right)^{2}+\left(\sum_{t} Q_{t}\right)^{2}\right]}}{3 I}
$$

which, after (23) is taken into account, is equal to

$$
\bar{U}=\sqrt{\frac{3\left[\left(\sum_{t} P_{t}\right)^{2}+\left(\sum_{t} Q_{t}\right)^{2}\right]}{\left(\sum_{t} \frac{P_{t}}{U_{f t}}\right)^{2}+\left(\sum_{t} \frac{Q_{t}}{U_{f t}}\right)^{2}}}
$$

For each MV/LV transformer the following quantities are known:

1) Rated values: $S_{N}, \Delta P_{F e N}, \Delta P_{C u N}, \Delta u_{z \%}, I_{0 \%}, U_{G N}, U_{D N}$ and the windings ratio correction $\Delta z_{\%}$, performed by means of a tap changer,

2) $D T_{h}$ (date and time, i.e. the timestamp), $\bar{P}_{h}, \bar{Q}_{h}, \bar{U}_{h}(\mathrm{~B} .11), h=1,2, ., H$.

Below a method of calculating power/energy losses in an hour-period is presented for an $\mathrm{r}$-th transformer $(\mathrm{r}=1,2, \ldots, \mathrm{R}, \mathrm{R}$ - number of transformers under scrutiny; a transformer index is omitted in further discussion). The following losses are obtained:

$\Delta P_{U h}-$ voltage loss of active power in the transformer core

$\Delta P_{I h}-$ current loss of active power in the transformer windings

$\Delta Q_{U h}-$ voltage loss of reactive power in the transformer core

$\Delta Q_{I h}-$ current loss of reactive power in the transformer windings

The voltage loss of active power in the transformer core is obtained from the formula:

$$
\Delta P_{U h}=\Delta P_{F e N} \frac{\bar{U}_{G h}^{2}}{U_{G N}^{2}}
$$

where: $\bar{U}_{G h}$-mean voltage in the $h$-th hour at the primary side of the transformer, obtained from the formula:

$\bar{U}_{G h}=\bar{U}_{h}\left(1+0,01 \cdot \Delta u_{T \% h}\right) \Theta$ 
where: $\bar{U}_{h}$ - voltage in the $h$-th hour at the secondary side of the transformer, $\Delta u_{T \% h}$ - relative voltage drop in the transformer for the $h$-th hour, $\Theta$ - real voltage winding ratio of the transformer (constant throughout the analysis), equal to:

$\Theta=\frac{U_{G N}}{U_{D N}}\left(1+0,01 \cdot \Delta z_{\%}\right)$

The relative voltage drop in the transformer for the $h$-th hour is obtained from the formula:

$$
\Delta u_{T \% h}=\left(\Delta u_{R N \%} \cos \varphi_{h}+\Delta u_{X N \%} \sin \varphi_{h}\right) \beta_{h}
$$

where:

$$
\beta_{h}=\frac{\sqrt{\bar{P}_{h}^{2}+\bar{Q}_{h}^{2}}}{S_{N}}
$$

is the load coefficient of the transformer.

The current loss of active power in the transformer windings $\Delta P_{I h}$ is obtained from the formula:

$$
\Delta P_{I h}=\Delta P_{C u N} \beta_{h}^{2} k_{T h}
$$

where: $k_{T h}$-temperature coefficient, allowing for the change in the resistance in the transformer windings depending on the load, equal [3] to:

$$
k_{T h}=0.3179 \cdot \beta_{h}^{2}-0.082 \cdot \beta_{h}+0.77
$$

The voltage loss of reactive power in the transformer core $\Delta Q_{U h}$ is obtained from the formula:

$$
\Delta Q_{U h}=\sqrt{\left(0.01 \cdot I_{0 \%} S_{N}\right)^{2}-\Delta P_{F e N}^{2}} \cdot \frac{\bar{U}_{G h}^{2}}{U_{G N}^{2}}
$$

The current loss of reactive power in the transformer windings $\Delta Q_{I h}$ is obtained from the formula:

$$
\Delta Q_{I h}=0.01 \cdot \Delta u_{X N \%} S_{N} \beta_{h}^{2}
$$




\section{Results}

The analysis was carried out on the basis of data from the year 2016, obtained from a distribution company in Poland. The data from consumer meters with active and reactive load for one year periods and transformers MV / LV were collected. The MV / LV transformer load data is shown in Table 1. Using the data on recipients' loads, the active energy load in transformers was calculated for every month of the year on the basis of formula (17) and reactive - on the basis of formula (18).

Table 1. Active and reactive energy flowing through MV/LV transformers for every month of the year.

Table 1

Active and reactive energy flowing through MV/LV transformers for every month of the year

\begin{tabular}{|c|c|c|c|c|c|c|}
\hline \multirow{2}{*}{} & \multicolumn{3}{|c|}{ Active energy [MWh] } & \multicolumn{3}{c|}{ Reactive energy [Mvarh] } \\
\cline { 2 - 7 } & $\begin{array}{c}160 \\
{[\mathrm{kVA}]}\end{array}$ & $\begin{array}{c}250 \\
{[\mathrm{kVA}]}\end{array}$ & $\begin{array}{c}400 \\
{[\mathrm{kVA}]}\end{array}$ & $\begin{array}{c}160 \\
{[\mathrm{kVA}]}\end{array}$ & $\begin{array}{c}250 \\
{[\mathrm{kVA}]}\end{array}$ & $\begin{array}{c}400 \\
{[\mathrm{kVA}]}\end{array}$ \\
\hline I & 341 & 869 & 1847 & 74 & 145 & 400 \\
\hline II & 294 & 739 & 1601 & 66 & 129 & 373 \\
\hline III & 294 & 758 & 1610 & 73 & 140 & 397 \\
\hline V & 272 & 678 & 1466 & 75 & 130 & 389 \\
\hline V & 271 & 675 & 1419 & 82 & 145 & 409 \\
\hline VI & 256 & 624 & 1304 & 83 & 143 & 390 \\
\hline VII & 242 & 640 & 1361 & 80 & 183 & 470 \\
\hline VIII & 246 & 640 & 1358 & 81 & 182 & 463 \\
\hline IX & 250 & 674 & 1425 & 68 & 147 & 417 \\
\hline X & 272 & 744 & 1625 & 69 & 154 & 469 \\
\hline XI & 286 & 779 & 1681 & 67 & 148 & 424 \\
\hline XII & 340 & 875 & 1824 & 75 & 148 & 404 \\
\hline
\end{tabular}

On the basis of the data, voltage and current losses of active and reactive energy were calculated. Results for the particular months are shown in Table 2. Voltage loss of active energy is obtained from formula (27) and reactive from formula (33). Current loss of active energy is obtained from formula (31) and reactive from formula (34).

As can be seen in Table 2 reactive energy loss in transformers is significantly higher than active energy loss. Besides, voltage losses, both of active and reactive energy are higher than current losses. The low amount of current losses is due to relatively low load coefficients of MV/LV transformers, varying from 0.138 for the group $160 \mathrm{kVA}$ to 0.148 for the group $400 \mathrm{kVA}$. 
Table 2

Active and reactive energy losses flowing through MV/LV transformers

\begin{tabular}{|c|c|c|c|c|c|c|c|}
\hline & \multirow[t]{2}{*}{$\begin{array}{l}\text { Power } \\
\mathrm{kVA}]\end{array}$} & \multirow[t]{2}{*}{$\begin{array}{l}\text { Number } \\
\text { of transf. }\end{array}$} & \multirow[t]{2}{*}{$\beta$} & \multicolumn{2}{|c|}{$\begin{array}{c}\text { Active energy } \\
\text { losses }\end{array}$} & \multicolumn{2}{|c|}{$\begin{array}{c}\text { Reactive energy } \\
\text { losses }\end{array}$} \\
\hline & & & & $\begin{array}{l}\text { Voltage } \\
\text { [MWh] }\end{array}$ & \begin{tabular}{|l} 
Current \\
[MWh]
\end{tabular} & $\begin{array}{l}\text { Voltage } \\
\text { [Mvarh] }\end{array}$ & \begin{tabular}{|l} 
Current \\
[Mvarh]
\end{tabular} \\
\hline \multirow{3}{*}{ I } & 160 & 18 & 0.163 & 4.8 & 0.90 & 48.3 & 3.2 \\
\hline & 250 & 30 & 0.158 & 15.5 & 2.17 & 111.0 & 8.8 \\
\hline & 400 & 47 & 0.172 & 23.3 & 5.90 & 194.7 & 22.9 \\
\hline \multirow{3}{*}{ II } & 160 & 18 & 0.156 & 4.4 & 0.75 & 43.7 & 2.7 \\
\hline & 250 & 30 & 0.149 & 14.0 & 1.73 & 100.2 & 7.1 \\
\hline & 400 & 47 & 0.165 & 21.1 & 4.86 & 176.2 & 19.0 \\
\hline \multirow{3}{*}{ III } & 160 & 18 & 0.142 & 4.8 & 0.70 & 48.3 & 2.5 \\
\hline & 250 & 30 & 0.138 & 15.4 & 1.69 & 110.8 & 6.9 \\
\hline & 400 & 47 & 0.151 & 23.2 & 4.52 & 194.2 & 17.8 \\
\hline \multirow{3}{*}{ IV } & 160 & 18 & 0.136 & 4.7 & 0.65 & 46.9 & 2.3 \\
\hline & 250 & 30 & 0.128 & 14.8 & 1.44 & 106.2 & 5.9 \\
\hline & 400 & 47 & 0.142 & 22.6 & 3.86 & 188.8 & 15.3 \\
\hline \multirow{3}{*}{ V } & 160 & 18 & 0.132 & 4.9 & 0.64 & 48.6 & 2.3 \\
\hline & 250 & 30 & 0.124 & 15.7 & 1.39 & 112.3 & 5.7 \\
\hline & 400 & 47 & 0.134 & 23.7 & 3.52 & 198.8 & 14.0 \\
\hline \multirow{3}{*}{ VI } & 160 & 18 & 0.130 & 4.7 & 0.60 & 47.0 & 2.2 \\
\hline & 250 & 30 & 0.119 & 15.2 & 1.28 & 108.7 & 5.2 \\
\hline & 400 & 47 & 0.128 & 23.0 & 3.14 & 192.5 & 12.5 \\
\hline \multirow{3}{*}{ VII } & 160 & 18 & 0.119 & 4.8 & 0.56 & 48.3 & 2.0 \\
\hline & 250 & 30 & 0.119 & 15.5 & 1.35 & 111.1 & 5.5 \\
\hline & 400 & 47 & 0.131 & 23.3 & 3.27 & 195.2 & 13.1 \\
\hline \multirow{3}{*}{ VIII } & 160 & 18 & 0.121 & 4.9 & 0.59 & 48.3 & 2.1 \\
\hline & 250 & 30 & 0.119 & 15.5 & 1.35 & 111.1 & 5.5 \\
\hline & 400 & 47 & 0.130 & 23.3 & 3.31 & 195.1 & 13.2 \\
\hline \multirow{3}{*}{ IX } & 160 & 18 & 0.125 & 4.7 & 0.58 & 46.9 & 2.1 \\
\hline & 250 & 30 & 0.128 & 15.0 & 1.43 & 107.7 & 5.8 \\
\hline & 400 & 47 & 0.139 & 22.6 & 3.60 & 189.2 & 14.3 \\
\hline \multirow{3}{*}{$X$} & 160 & 18 & 0.131 & 4.9 & 0.64 & 48.4 & 2.3 \\
\hline & 250 & 30 & 0.136 & 15.5 & 1.66 & 111.1 & 6.8 \\
\hline & 400 & 47 & 0.153 & 23.4 & 4.57 & 195.5 & 18.0 \\
\hline \multirow{4}{*}{ XI } & 160 & 18 & 0.142 & 4.7 & 0.71 & 46.7 & 2.5 \\
\hline & 250 & 30 & 0.147 & 15.0 & 1.85 & 107.4 & 7.6 \\
\hline & 400 & 47 & 0.163 & 22.6 & 5.09 & 189.0 & 19.9 \\
\hline & 160 & 18 & 0.163 & 4.8 & 0.92 & 48.3 & 3.3 \\
\hline
\end{tabular}




\begin{tabular}{|c|c|c|c|c|c|c|c|}
\hline \multirow{2}{*}{ XII } & 250 & 30 & 0.159 & 15.4 & 2.25 & 110.6 & 9.1 \\
\cline { 2 - 8 } & 400 & 47 & 0.170 & 23.2 & 5.77 & 193.8 & 22.5 \\
\hline Year & & & $\mathbf{0 . 1 4 2}$ & $\mathbf{5 1 6}$ & $\mathbf{7 9}$ & $\mathbf{4 1 8 2}$ & $\mathbf{3 1 3}$ \\
\hline
\end{tabular}

Using the formula:

$$
\eta_{E}=\frac{E_{c}}{E_{c}+\Delta E_{c U}+\Delta E_{c I}}
$$

the average efficiency of active energy transfer was obtained. The results are presented in Fig. 2.

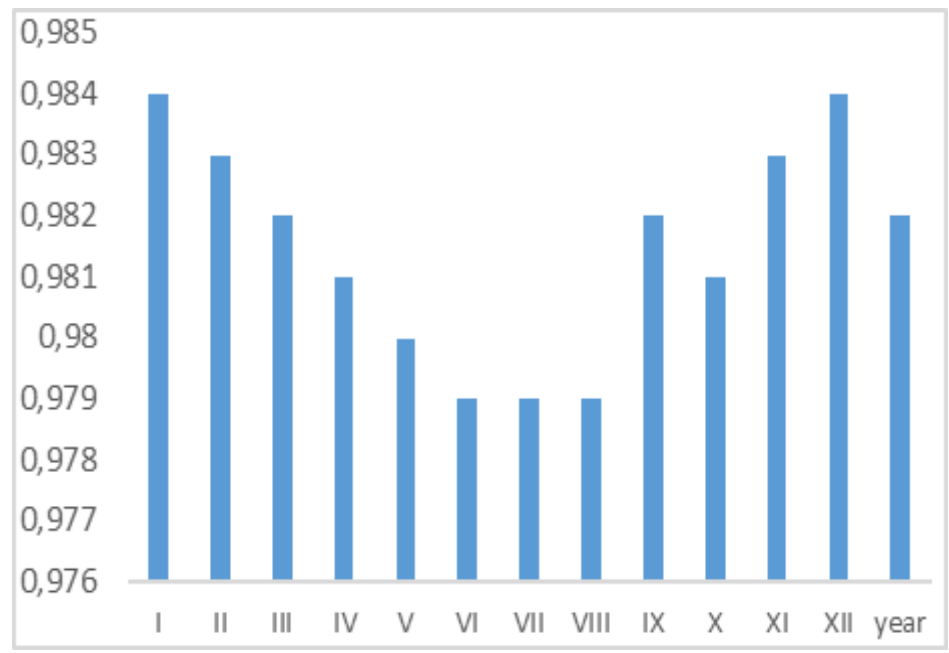

Figure 2

Average efficiency of energy transfer

The highest efficiency of energy transfer in MV/LV transformers occurs in winter and the lowest in summer. This is connected, among other factors, with voltage losses, which are practically constant throughout the year, so when the amount of energy flowing through transformers is lower as it is in summer, the network efficiency is also lower.

Extremely low transformer load coefficients generate high active and reactive energy loss. Taking this into consideration, a simulation experiment was carried out for the period of a year, in which the transformer load was adjusted to the amount of energy flowing through them. The results are presented in Table 3. 
Table 3

Active and reactive energy loss after the transformer power has been adjusted to load

\begin{tabular}{|c|c|c|c|c|c|c|}
\hline \multicolumn{7}{|c|}{ Current condition } \\
\hline \multirow{2}{*}{$\begin{array}{l}\text { Power } \\
{[\mathrm{kVA}]}\end{array}$} & \multirow{2}{*}{$\begin{array}{l}\text { Number of } \\
\text { transf. }\end{array}$} & \multirow[t]{2}{*}{$\beta$} & \multicolumn{2}{|c|}{ Active energy losses } & \multicolumn{2}{|c|}{ Reactive energy losses } \\
\hline & & & $\begin{array}{l}\text { Voltage } \\
\text { [MWh] }\end{array}$ & $\begin{array}{l}\text { Current } \\
\text { [MWh] }\end{array}$ & $\begin{array}{l}\text { Voltage } \\
\text { [Mvarh] }\end{array}$ & $\begin{array}{l}\text { Current } \\
\text { [Mvarh] }\end{array}$ \\
\hline 160 & 18 & 0.138 & 57.723 & 8.291 & 570.299 & 29.972 \\
\hline 250 & 30 & 0.135 & 183.208 & 19.642 & 1308.847 & 80.583 \\
\hline 400 & 47 & 0.148 & 275.788 & 51.450 & 2303.423 & 203.312 \\
\hline total & 516.719 & 79.383 & 4182.569 & 313.867 & 516.719 & 79.383 \\
\hline \multicolumn{7}{|c|}{ Transformer power adjusted to load } \\
\hline \multirow{2}{*}{$\begin{array}{l}\text { Power } \\
{[\mathrm{kVA}]}\end{array}$} & \multirow{2}{*}{$\begin{array}{c}\text { Number of } \\
\text { transf. }\end{array}$} & \multirow[t]{2}{*}{$\beta$} & \multicolumn{2}{|c|}{ Active energy losses } & \multicolumn{2}{|c|}{ Reactive energy losses } \\
\hline & & & $\begin{array}{l}\text { Voltage } \\
\text { [MWh] }\end{array}$ & $\begin{array}{l}\text { Current } \\
\text { [MWh] }\end{array}$ & $\begin{array}{l}\text { Voltage } \\
\text { [Mvarh] }\end{array}$ & $\begin{array}{l}\text { Current } \\
\text { [Mvarh] }\end{array}$ \\
\hline 63 & 22 & 0.351 & 31.910 & 9.2199 & 352.674 & 19.977 \\
\hline 75 & 31 & 0.451 & 95.76 & 75.997 & 580.455 & 191.412 \\
\hline 160 & 42 & 0.37 & 118.652 & 106.546 & 1172.281 & 385.164 \\
\hline total & 246.323 & 191.762 & 2105.410 & 596.552 & 246.323 & 191.762 \\
\hline
\end{tabular}

It follows that when the transformer power was adjusted to the load, the active energy loss was reduced by $26.5 \%$, and the reactive energy loss by $40 \%$.

\section{Conclusions}

It has been demonstrated that transformers are characterized by a low load coefficient, which is evidenced by high voltage energy loss, significantly exceeding current energy loss.

The highest value of the power coefficient $(\cos \varphi)$, equal to $0.952(\operatorname{tg} \varphi=0.323)$ was attested in December and the lowest value equal to $0.916(\operatorname{tg} \varphi=0.437)$ in June. For the whole year, these values for the primary transformer winding are (respectively) $\cos \varphi=0.932, \operatorname{tg} \varphi=0.390$. The relatively high power coefficient is affected by the batteries of parallel capacitors connected to the low voltage side of $\mathrm{MV} / \mathrm{LV}$ transformers as compensation for the idle state.

The study has found that the low efficiency of energy distribution is caused by low load in MV/LV transformers. The extremely low load coefficient contributes to high reactive energy loss, thereby lowering the network efficiency. It follows that transformer power should be adequately adjusted to the load, which will significantly reduce the energy losses.

\section{Acknowledgement}

The Ministry of Education, Science, Research and Sport of the Slovak Republic and the Slovak Academy of Sciences under the contract no. VEGA 1/0372/18 supported this work. 


\section{References}

[1] Nawrowski, R., Stein, Z., and Zielińska, M.: Analiza wpływu przekraczania dopuszczalnych wartości współczynnika mocy w sieci nn na pracę systemu elektroenergetycznego, Electrical Engineering, No. 74, 2013, pp. 111-117

[2] Pozna, ., Precup, R., Tar, J., Škrjanc, I., Preitl, S.: New results in modelling derived from Bayesian filtering, Knowledge-Based Systems, Vol. 23, No. 2, 2010, pp. 182-194

[3] Niewiedział, E., and Niewiedział, R.: Problematyka strat mocy i energii w transformatorach rozdzielczych SN/nn, Electro.info 10/2017

[4] Gawlak, A.: Technological aspects of electrical energy distribution. 14 $4^{\text {th }}$ International Scientific Conferenc Electric Power Engineering 2014, May 2014, Brno Czech Republic ISBN 978-80-214-4514-7

[5] Zajkowski, K.: Analiza szacunkowa w audycie energetycznym rozliczająca działania zmniejszające przepływy mocy biernej w sieci energetycznej, Logistyka 6/2014

[6] Ürmös, A., Farkas, Z., Farkas, M., Sándor, T., Kóczy, L.T., and Nemcsics, A.: Application of self-organizing maps for technological support of droplet epitaxy, Acta Polytechnica Hungarica, Vol. 14, No. 4, 2017, pp. 207-224

[7] Kolcun, M., Kornatka, M., Gawlak, A., and Čonka, Z.: Benchmarking the reliability of medium-voltage lines, Journal of Electrical Engineering, Vol. 68 (3), 2017 r, pp. 212-215

[8] Ürmös, A., Farkas, Z., Farkas, M., Sándor, T., Kóczy, L. T., and Nemcsics, A.: Model-free sliding mode and fuzzy controllers for reverse osmosis desalination plants, International Journal of Artificial Intelligence, Vol. 16, No. 2, 2018, pp. 208-222

[9] Bielecki, S.:Ookreślanie strat powodowanych obciążeniem mocą bierną metoda nie wykorzystująca pojęcia energetycznego równoważnika mocy biernej, Przegląd Elektrotechniczny, issn 0033-2097, r. 94 nr 9/2018

[10] Ustawa z dnia 20 maja 2016r. o efektywności energetycznej. Dz.U. z 2016 r. poz. 831

[11] Precup, R., and Preitl, S.: Stability and sensitivity analysis of fuzzy control systems. Mechatronics applications, Acta Polytechnica Hungarica, Vol. 3, No. 1, pp. 61-76, 2006

[12] Gawlak, A.: Analysis of technical losses in the low and medium voltage power network. $11^{\text {th }}$ International Scientific Conference Electrical Power Engineering - EPE 2010, Brno Czech Republic, ISBN 978-80-214-4094-4 pp. 119-123) 
[13] Gawlak, A.: The Influence of Investment on Reducing Energy Losses in Distribution Networks, in Proc. $16^{\text {th }}$ International Scientific Conference on Electric Power Engineering, 2015r, pp. 315-319

[14] Gawlak, A.: Podział środków inwestycyjnych na rozwój sieci rozdzielczych przy zastosowaniu metody taksonomicznej, Przegląd Elektrotechniczny, R.85 nr 3, 2009 r, pp. 57-160

[15] Kornatka, M., and Gawlak, A.: Comparative Analysis of Operating Conditions in Polish Medium-voltage and $110 \mathrm{kV}$ Networks, in Proc. $8^{\text {th }}$ International Scientific Symposium on Electrical Power Engineering, 2015 r, pp. 57-60

[16] Gono, M., Knycl, M., Gono, R., and Kłosok-Bazan, I.: Experience with the production of electricity from biogas at sewage treatment plant in the Czech Republic, Przeglad Elektrotechniczny, Volume 89, Issue 11, 2013 r, pp. 1215

[17] Gawlak, A.: Noninvestment Forms of Reducing Energy Losses in Distribution Networks, in Proc. $8^{\text {th }}$ International Scientific Symposium on Electrical Power Engineering, 2015, pp. 61-64

[18] Czepiel, S.: Transfiguration of Supplied-by-HV/MV Transformer Network to the Supply Radius, Electrical Power Quality and Utilization, Journal, ISSN 1234-6799, Volume XIV - Number 1 - 2008 